\title{
Immunohistochemical diagnosis of canine ovarian epithelial and granulosa cell tumors
}

\author{
Elena Riccardi, Valeria Greco, ${ }^{1}$ Sara Verganti, Mario Finazzi
}

\begin{abstract}
In humans and canines, the morphology of granulosa cell tumors is extremely variable and causes diagnostic difficulties. In human pathology, immunohistochemistry has been widely used for the diagnosis of granulosa cell tumors, whereas, limited studies are present in canine species. The aim of this study was to investigate the expression of cytokeratins, vimentin, and inhibin- $\alpha$ in canine normal ovaries, epithelial ovarian tumors, and granulosa cell tumors to establish an immunohistochemical panel for the differential diagnosis of ovarian tumors. Formalin-fixed, paraffin-embedded tissue sections from 4 normal ovaries, 8 granulosa cell tumors, and 6 epithelial ovarian tumors (2 adenomas and 4 adenocarcinomas) sections were obtained and stained with hematoxylin and eosin and immunohistochemically for cytokeratin AE1/AE3, cytokeratin 7, vimentin, and inhibin- $\alpha$. In normal ovaries, cytokeratin 7 , cytokeratin AE1/AE3, and vimentin were expressed in the surface epithelium. Granulosa cells were negative for cytokeratin 7 and displayed variable expression of vimentin, cytokeratin AE1/AE3, and inhibin- $\alpha$ toward follicular maturation. Granulosa cell tumors were negative for cytokeratin 7 and positive for inhibin- $\alpha$. Conversely, ovarian epithelial cells tumors were positive for cytokeratin 7 and negative for inhibin- $\alpha$. Both granulosa and epithelial cell tumors displayed variable expression of vimentin. Cytokeratin AE1/AE3 was expressed by all epithelial-derived tumors and 6 of 8 granulosa cell tumors. The results of this study suggest that useful immunohistochemical markers to distinguish epithelial ovarian tumors from granulosa cell tumors are cytokeratin 7 and inhibin- $\alpha$.
\end{abstract}

Key words: Canine; cytokeratin 7; granulosa cells tumor; immunohistochemistry; inhibin- $\alpha$; ovarian neoplasia; ovary.

In human, as in canine species, granulosa cell tumors (GCT) are considered uncommon low-grade malignant neoplasms that rarely metastasize. ${ }^{8,14,17}$ Because of the extremely variable histologic appearance of GCTs, they may be confused with ovarian epithelial tumors. ${ }^{15,20}$ Distinguishing between these 2 types of tumors has great prognostic significance, because ovarian epithelial tumors are frequently malignant and metastatic. ${ }^{17}$ The pattern of expression of citokeratins (CK) and vimentin (VIM) in granulosa cells of normal ovaries and in GCTs is well known. ${ }^{1,3,18,19}$ In human pathology, immunohistochemistry is used in the diagnosis of these tumors as an adjunct to morphology. ${ }^{12}$

Cytokeratins are intermediate filaments characteristically found in epithelial cells and their tumors. Cytokeratins comprised a family of at least 20 different polypeptides, numbered consecutively from 1 to 20 , according to differences in molecular weight and isoelectric $\mathrm{pH} .{ }^{3} \mathrm{CK} 7$, a basic keratin found in the glandular epithelium of different organs, such as endometrium, mammary gland, and the ovarian surface epithelium, is also present in ovarian adenomas and carcinomas. ${ }^{2,16}$ Vimentin is usually detected in granulosa cells of normal ovarian follicles and in GCTs. ${ }^{1,3,19}$ Inhibin- $\alpha(\mathrm{INH} \alpha)$ is a sensitive and specific immunohistochemical marker for GCTs. ${ }^{15}$ Inhibin- $\alpha$ is a disulphide-linked glycoprotein dimer that belongs to the

From the Department of Pathology, Section of Veterinary Pathology and Avian Pathology, Veterinary Faculty, University of Milan, Via Celoria 10, 20133, Milan, Italy.

${ }^{1}$ Corresponding Author: Valeria Grieco, Sezione di Anatomia Patologica, Facoltà Veterinaria, Via Celoria 10, 20133 Milano Italy. valeria.grieco@unimi.it
Transforming Growth Factor- $\beta$ peptide family. The gonadal site of INH $\alpha$ synthesis is the granulosa cells compartment. ${ }^{4}$ Inhibin- $\alpha$ inhibits the production of Follicle Stimulating Hormone from the pituitary gland and is involved in follicular growth and differentiation. ${ }^{4}$

Morphologic features of canine GCTs have been reported. ${ }^{14}$ The histologic appearance of these tumors in the $\operatorname{dog}$ is variable, ranging from the most common follicular to solid and Sertoli-like patterns. ${ }^{14}$ Moreover, the immunohistochemical profile of granulosa cells in normal canine ovaries and GCTs has been rarely reported and was limited to INH $\alpha$ expression. ${ }^{10,11}$

The purpose of the present study was to investigate the morphology of GCTs and the immunophenotype of granulosa cells in normal canine ovaries and related tumors, in an attempt to provide a helpful immunohistochemical panel for the differential diagnosis of GCTs from ovarian epithelial tumors.

Four normal canine ovaries, 14 ovarian neoplasms from 7- to 14-year-old bitches, previously diagnosed as GCTs (8 cases) and as primary ovarian epithelial tumors (6 cases), were collected from the archives of the authors' department. All the samples were fixed in $10 \%$ neutral buffered formalin, processed by conventional methods, and paraffin embedded. For each tumor, 2 to 4 paraffin blocks were available. For each sample, 5- $\mu$ m-thick sections were obtained and stained with hematoxylin and eosin. Canine GCTs were classified according to the human classification. ${ }^{17}$ Growth patterns of canine GCTs were microfollicular, macrofollicular, trabecular, solid, and sarcomatoid. The presence of Sertoli cell differentiation was also recorded. Immunohistochemical staining of both normal 

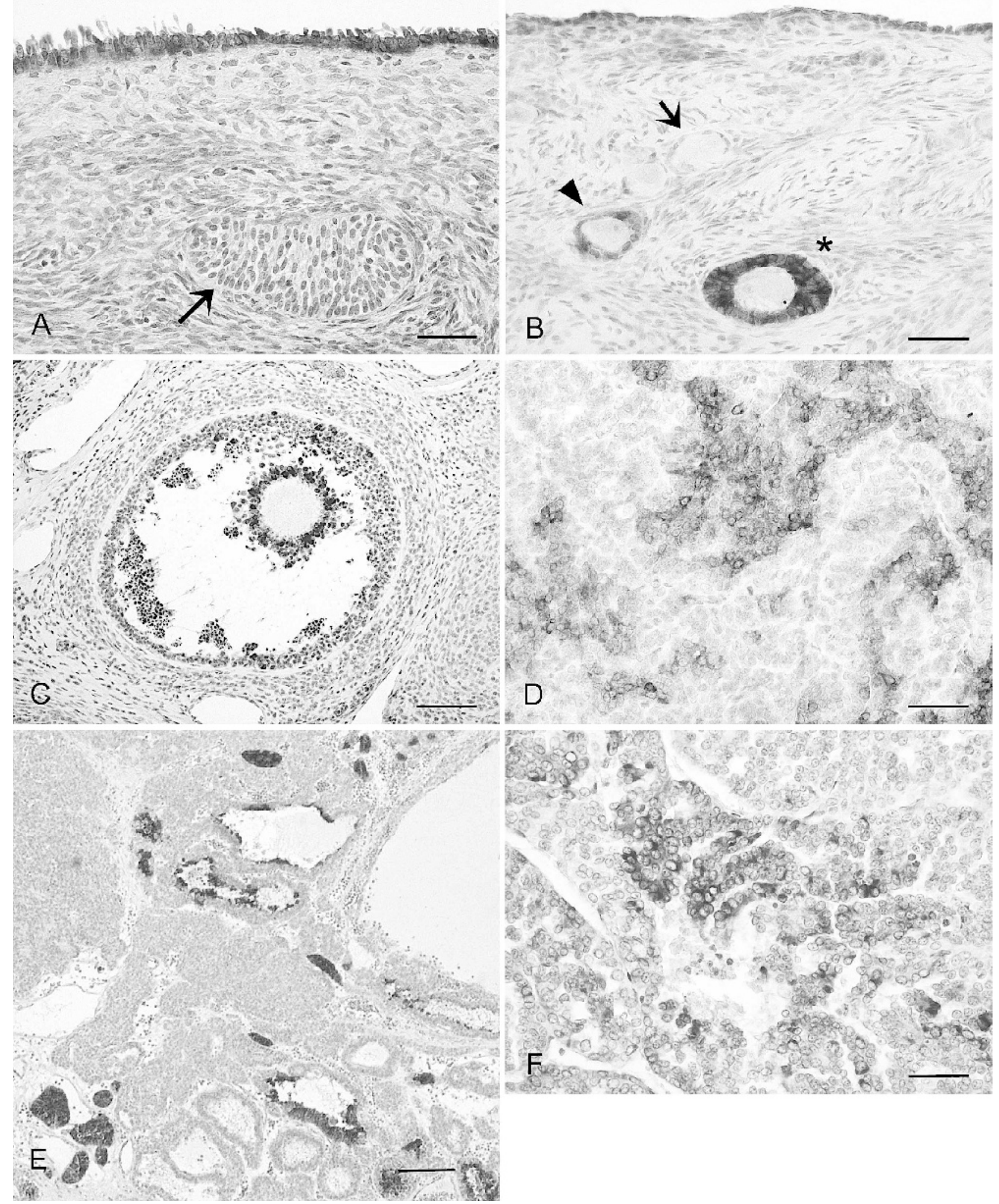

Figure 1. Immunohistochemical (IHC) expression of cytokeratin (CK) 7 and INH in normal (A, B, C) and neoplastic (D, E, F) canine ovaries. A, Normal ovary; adult bitch. Surface epithelial cells show a strong and diffuse staining for CK 7. Granulosa cells are completely negative (arrow). IHC stain. Bar $=50 \mu \mathrm{m}$. B, Normal ovary; adult bitch. Expression of INH $\alpha$ is faint in granulosa cells of primordial follicle (arrow) and increase in primary (arrowhead) and secondary (asterisk) follicles. The surface epithelial cells are negative. IHC stain. Bar $=50 \mu \mathrm{m}$. C, Normal ovary; adult bitch. Expression of INH $\alpha$ in granulosa cells in a Graafian follicle. Positivity 
Table 1. Immunohistochemical findings in normal canine ovaries.

\begin{tabular}{lcccc}
\hline \hline \multicolumn{1}{c}{ Ovarian structure } & CK AE1/AE3* & VIM $^{*}$ & CK 7* & INH $\alpha^{*}$ \\
\hline Oocytes & - & - & - & - \\
Granulosa cells & & & & \\
$\quad$ Primordial follicle & +++ & - & - & + \\
$\quad$ Primary follicle & +++ & +++ & - & +++ \\
Secondary follicle & ++ & +++ & - & +++ \\
Graafian follicle & + & +++ & - & + \\
Cumulus & ++ & +++ & - & +++ \\
Corpus luteum & + & ++ & - & - \\
Theca & + & ++ & - & - \\
Stroma & - & +++ & - & - \\
Surface epithelium & ++ & + & +++ & - \\
\hline
\end{tabular}

* $\mathrm{CK}=$ cytokeratin; VIM $=$ vimentin; INH $\alpha=$ inhibin $-\alpha ;-=$ negative; $+=$ less than $10 \%$ of cells stained; $++=10 \%-30 \%$ of cells stained; $+++=30 \%-60 \%$ of cells stained; $++++=60 \%-90 \%$ of cells stained.

and neoplastic ovaries was performed on deparaffinized sections by using the avidin-biotin-peroxidase complex technique $^{\mathrm{a}}$ procedure $^{7}$ for INH- $\alpha^{\mathrm{b}}$ (mouse monoclonal antibody, clone R1, diluted at 1:50), $\mathrm{VIM}^{\mathrm{c}}$ (mouse monoclonal antibody, clone 3B4, diluted at 1:1,000), CK AE1/ $\mathrm{AE}^{\mathrm{d}}$ (mouse monoclonal antibody, clone AE1/AE3 diluted at $1: 3,000), \mathrm{CK} 7^{\mathrm{c}}$ (mouse monoclonal antibody, clone OV-TL 12/30, diluted at 1:200). The primary antibodies were incubated overnight at $4{ }^{\circ} \mathrm{C}$. Antigen retrieval was done for INH $\alpha$ by microwaving for $8 \mathrm{~min}$ on $\mathrm{pH} 6$ citrate buffer; for $\mathrm{CK}$ AE1/AE3 and CK 7, by incubating for $15 \mathrm{~min}$ at $37^{\circ} \mathrm{C}$ with pepsin; for VIM antigen retrieval was not required. Negative controls were performed under identical conditions, replacing the primary antibody with normal horse serum. Sections were incubated with normal horse serum before the primary antibody. Diaminobenzidine tetrahydrochloride ${ }^{a}$ or 3-amino-9-ethylcarbazole $^{\text {a }}$ were used as chromogens. Sections were counterstained with Mayer hematoxylin.

The staining was scored as $4+(60 \%-100 \%$ of neoplastic cells stained), $3+(30 \%-60 \%$ of cells stained), $2+(10 \%-30 \%$ of cells stained), and 1+ (less than $10 \%$ of cells stained).

Immunohistochemical findings are presented in Table 1. Surface epithelium was diffusely and strongly positive for both CK AE1/AE3 and CK 7 (Fig. 1A). Epithelial cells were also faintly stained for VIM, and the positive signal was mainly restricted to the basal region of the cytoplasm. Oocytes were constantly negative for all the antibodies used. Granulosa cells were negative for CK 7 and stained positively for INH $\alpha, \mathrm{CK}$ AE1/AE3, and VIM, with some differences, according to the developmental stage of the follicles. Inhibin- $\alpha$ was faintly expressed in primordial follicles, increased in primary and secondary follicles (Fig. 1B), whereas, in Graafian follicles, it was mainly restricted to the granulosa cells of the cumulus (Fig. 1C). Cytokeratin AE1/AE3 staining was strong in primordial follicles and gradually decreased throughout follicular maturation. Immunostaining for VIM was first detected in primary follicles and subsequent developmental stages. Corpora lutea stained positively for VIM and CK AE1/ AE3, and were negative for INH $\alpha$ and CK 7.

The 8 GCTs exhibited a variable histologic appearance, as illustrated in Table 2. Follicular, trabecular, Sertoli-like, diffuse (solid), and sarcomatoid patterns were observed. More than 1 histologic pattern coexisted in each tumor, and the prevailing types were microfollicular and diffuse (solid). Moreover, in 3 cases, neoplastic cells palisading tubules in a Sertoli-like appearance were also observed. Neoplastic cells were moderately pleomorphic, small, round to oval in shape, had indistinct borders, and a scant to moderate amount of pale eosinophilic cytoplasm. Nuclei were generally round to oval and hyperchromatic, with dense chromatin. In areas exhibiting a solid growth pattern, neoplastic cells were polygonal with abundant cytoplasm, round-to-oval nuclei and marginated chromatin.

Immunohistochemical findings of the tumors examined are presented in Table 2. Six (75\%) of GCTs reacted positively with anti-INH $\alpha$ antibody. The distribution of immunoreactivity for INH $\alpha$ was extremely variable, and the percentage of positive-labeled neoplastic cells ranged from $5 \%$ to $50 \%$ (Fig. 1D, 1E). Six (75\%) of GCTs were positive for CK AE1/AE3. The percentage of positive neoplastic cells ranged from $50 \%$ to $90 \%$. The intensity of the staining was extremely variable, and strongly and weakly positive-stained neoplastic cells coexisted within the same area. All the GCTs examined reacted positively for VIM, and the percentage of positive cells stained ranged from $10 \%$ to $90 \%$. The 2 GCTs negative for INH $\alpha$ showed strong immunostaining for CK 7 (Table 2, cases no. 3 and 7). Because of this latter finding, the tumors were both reclassified as ovarian-epithelium-derived tumors ( $\mathrm{Ta}$ ble 2). The other 6 GCTs were totally negative for CK 7.

Six ovarian epithelial tumors were examined. Two of them were diagnosed as adenoma and 4, showing stromal invasion, as adenocarcinomas (Table 2). All the tumors were composed of cystic and tubular or papillary structures, lined by cuboidal-to-columnar neoplastic cells characterized by a moderate amount of eosinophilic cytoplasm and round-to-oval basal nuclei. All the tumors reacted positively for $\mathrm{CK} A E 1 / \mathrm{AE} 3$. All the tumors reacted positively for VIM, and the percentage of positive labeled neoplastic cells ranged from $10 \%$ to $90 \%$ (Table 2).

Four of 6 epithelial tumors were strongly positive for CK 7 (Fig. 1F). The 2 cases reacting negative for CK 7 stained

$\leftarrow$

is mainly restricted to granulosa cells of the cumulus. IHC stain. Bar $=90 \mu \mathrm{m}$. D, Granulosa cell tumor. 13-year-old, female Boxer dog, case no. 10. Numerous neoplastic cells display strong expression of INH $\alpha$. IHC stain. Bar $=120 \mu \mathrm{m}$. E, Granulosa cell tumor. 10-yearold, female mixed breed dog, case no. 5. Strong, multifocal staining for INH $\alpha$. IHC stain. Bar $=50 \mu$ m. F, Ovarian adenocarcinoma. 9year-old, female Setter dog, case no. 7. Neoplastic cells positive for CK 7 indicate the origin of the tumor from the ovarian epithelial surface. IHC stain. Bar $=50 \mu \mathrm{m}$. 
Table 2. Histologic and immunohistochemical findings in 14 canine ovarian tumors.

\begin{tabular}{clcccccc}
\hline \hline Case no. & \multicolumn{1}{c}{ Growth pattern } & First diagnosis & CK AE1/AE3* & VIM* & CK 7* & INH $\alpha^{*}$ & Final diagnosis \\
\hline 1 & Trabecular/diffuse & GCT & +++ & ++++ & - & + & GCT \\
2 & Microfollicular/diffuse/Sertoli like & GCT & - & + & - & + & GCT \\
3 & Diffuse (solid) & GCT & ++++ & ++++ & ++++ & - & AC* \\
4 & Microfollicular/Sertoli-like & GCT & ++++ & + & - & + & GCT \\
5 & Macrofollicular/diffuse (solid) & GCT & ++++ & + & - & + & GCT \\
6 & Diffuse (solid)/Sertoli-like & GCT & ++++ & +++ & - & +++ & GCT \\
7 & Diffuse (solid)/macrofollicular & GCT & ++++ & + & ++++ & - & AC \\
8 & Microfollicular & GCT & - & ++ & - & ++++ & GCT \\
9 & Cystic papillary & AC & ++ & + & - & ++ & GCT \\
10 & Diffuse (solid) & AC & +++ & ++ & - & +++ & GCT \\
11 & Tubulopapillary & AC & ++++ & ++++ & +++ & - & AC \\
12 & Tubulopapillary & A & ++++ & + & ++++ & - & A \\
13 & Cystic papillary & AC & ++++ & + & ++++ & - & AC \\
14 & Tubular & A & ++++ & ++++ & ++++ & - & A \\
\hline
\end{tabular}

* $\mathrm{CK}=$ cytokeratin; VIM $=$ vimentin; INH $\alpha=$ inhibin $\alpha$; GCT $=$ granulosa cell tumor; $\mathrm{AC}=$ adenocarcinoma; $\mathrm{A}=$ adenoma

positively for INH $\alpha$. Because of this latter finding, both tumors were reclassified as GCTs.

In humans and in canines, GCTs are uncommon lowgrade malignant neoplasms that, displaying an extremely variable histologic appearance, may represent a diagnostic challenge with other ovarian neoplasms, mainly derived from the epithelial surface. ${ }^{15,20}$ In fact, although the classical follicular growth patterns of GCTs are readily recognizable on routine histologic sections, some variants with a solid or sarcomatoid pattern may be mistaken for other malignancies. ${ }^{15,20}$ Immunohistochemical has been used as a diagnostic tool for the differential diagnosis of ovarian tumors in humans. ${ }^{1,2,19}$ Cytokeratin 7 is selectively expressed by normal and neoplastic ovarian surface epithelium, 16,18,19 whereas, granulosa cells strongly react with anti-INH $\alpha$ antibodies.., 15

In normal canine ovaries, surface epithelial cells were negative for INH $\alpha$, strongly immunostained for CK AE1/ AE3 and CK 7, and faintly expressed VIM. The coexpression of CKs and VIM in ovarian surface epithelium is not surprising based on its embryonic origin from the coelomic epithelium, which displays similar coexpression. ${ }^{9}$

Granulosa cells of ovarian follicles in all stages of development showed the presence of both CK AE1/AE3 and VIM, with some differences, depending on their developmental stage. In fact, although in granulosa cells of primary and secondary follicles, CK AE1/AE3 were strongly represented, in the Graafian follicles, the number of positive cells decreased considerably. On the contrary, immunostaining for VIM in granulosa cells usually remained unchanged during all the follicular development. The coexpression of CKs and VIM in ovarian granulosa cells has also been described in the human literature. ${ }^{1,3,9}$ This finding is supported by the origin of granulosa cells from mesonephric-duct epithelium, where this coexpression has been observed. ${ }^{6}$

In normal canine ovaries, the surface epithelium was negative for INH $\alpha$, whereas granulosa cells were always, and consistently, positively immunolabeled. However, the number of positive cells and the intensity of the immunostaining decreased during follicular maturation. Because INH $\alpha$ inhibits follicular maturation, its decreasing in Graafian follicles is consistent with the physiologic role of this hormone during follicular maturation. ${ }^{4}$ Because, in some cases, the histologic features did not allow an unequivocal diagnosis, the expression of the immunohistochemical markers observed on normal ovary was applied to discriminate the origin of the ovarian tumors considered in this study.

Cytokeratin AE1/AE3 was expressed in all the tumors derived from ovarian epithelium and in 6 of 8 GCTs. The negative labeling for CK AE1/AE3 may help to exclude the epithelial origin of the neoplasm.

Vimentin expression, paralleling the results obtained in normal ovaries, was detected in all the tumors examined. This finding suggests that VIM is not a useful marker to discriminate among sex-cord and epithelial-derived ovarian tumors. Among the antibodies used, INH $\alpha$ and $\mathrm{CK} 7$ were determinant to differentiate between GCTs and ovarian epithelial derived tumors. In fact, on the basis of these 2 markers, 2 of 8 tumors previously diagnosed as GCTs, negative for INH $\alpha$ and positive for $\mathrm{CK} 7$, were reclassified as ovarian-epithelial-derived tumors. Conversely, 2 of 6 tumors previously considered of epithelial origin were negative for CK 7 and positive for INH $\alpha$, and were reclassified as GCTs (Table 2).

In the absence of $\mathrm{CK} 7$, the percentage of INH $\alpha$-positive cells in GCTs was extremely variable among the tumors examined (Table 2), and, within the same tumor, positive and negative neoplastic areas closely coexisted. Therefore, for diagnostic purposes, because GCTs are frequently large masses, the collection of several samples and the examination of different sections of the same neoplasm are recommended to avoid false-negative results. In GCTs, the percentage of INH $\alpha$-immunolabeled neoplastic cells differed among the tumors examined. A decrease in the expression of a selective marker is generally considered as an indicator of dedifferentiation of neoplastic cells. ${ }^{13}$ As previously mentioned, granulosa cells decrease their INH $\alpha$ expression during follicular maturation; a faint immunostaining for this marker in GCTs is suggestive of an origin from granulosa cells of more differentiated follicles.

In conclusion, because ovarian neoplasms usually do not have distinctive histologic features, immunohistochemistry 
is recommended to allow a reliable diagnosis. In summary, of all 4 immunohistochemical markers examined, CK 7 and INH $\alpha$ helped to distinguish ovarian-epithelial tumors from GCTs, and their use in difficult cases is recommended. However, a large series of cases, including other ovarian neoplasms, should be examined to confirm the results of the present study.

Acknowledgement. We thank Mr. Marco Colombo for photographic support.

\section{Sources and manufacturers}

a. Vector Laboratories, Burlingame, CA.

b. Serotec Co., Oxford, UK.

c. Dako Co., Carpinteria, CA.

d. Zymed Laboratories, San Francisco, CA.

\section{References}

1. Benjamin E, Law S, Borrow LG: 1987, Intermediate filaments cytokeratin and vimentin in ovarian sex cord-stromal tumors with correlative studies in adult and fetal ovaries. J Pathol 152:253-263

2. Cathro HP, Stoler MH: 2002, Expression of cytokeratin 7 and 20 in ovarian neoplasia. Am J Clin Pathol 117:944-951.

3. Czernobilsky B, Moll R, Levy R, Franke WW: 1985, Coexpression of cytokeratin and vimentin filaments in mesothelial, granulosa and rete ovarii cells of the human ovary. Eur J Cell Biol 37:175-190.

4. Gilchrist RB, Ritter LJ, Armstrong DT: 2004, Oocyte-somatic cell interactions during follicle development in mammals. Anim Reprod Sci 82-83:431-446.

5. Hildebrandt RH, Rouse RV, Longacre TA: 1997, Value of inhibin in the identification of granulosa cell tumors of the ovary. Hum Pathol 28:1387-1395.

6. Holthofer H, Miettinen A, Paasivuo R, et al.: 1984, Expression of vimentin and cytokeratin types of intermediate filament proteins in developing and adult human kidney. Lab Invest 50:552-559.

7. Hsu SM, Raine L, Fanger H: 1981, Use of avidin-biotinperoxidase complex (ABC) in immunoperoxidase techniques: a comparison between $\mathrm{ABC}$ and unlabeled antibody (PAP) procedures. J Histochem Cytochem 29:577-580.
8. Kennedy PC, Cullen JM, Edwards JF, et al.: 1998, Histological classification of tumors of the genital system of domestic animals. In: World Health Organization International histological classification of tumors of domestic animals, 2nd series, vol. IV, Armed Forces Institute of Pathology, Washington, DC.

9. Loffler S, Horn LC, Weber W, Spanel-Borowski K: 2000, The transient disappearance of cytokeratin in human fetal and adult ovaries. Anat Embryol (Berl) 201:207-215.

10. Marino G, Nicotina PA, Catone G, et al.: 2003, Alpha-inhibin expression in canine ovarian neoplasms: preliminary results. Vet Res Commun 27:237-240.

11. Marino G, Zanghi A, Catone G, et al.: 2003, Expression of inhibin/activin $\alpha, \beta A$ and $\beta B$ subunits in the ovary of the bitch. Vet Res Commun 27:611-614.

12. McCluggage WG: 2000, Recent advances in immunohistochemistry in the diagnosis of ovarian neoplasms. J Clin Pathol 53:327-334.

13. Moll R: 1994, Cytokeratins in the histological diagnosis of malignant tumors. Int J Biol Markers 9:63-69.

14. Patnaik AK, Greenlee PG: 1987, Canine ovarian neoplasms: a clinicopathologic study of 71 cases, including histology of 12 granulosa cell tumors. Vet Pathol 24:509-514.

15. Pelkey TJ, Frierson HF, Mills Jr SE, Stoler MH: 1998, The diagnostic utility of inhibin staining in ovarian neoplasms. Int J Gynecol Pathol 17:97-105.

16. Ramaekers F, van Niekerk C, Poels L, et al.: 1990, Use of monoclonal antibodies to keratin 7 in the differential diagnosis of adenocarcinomas. Am J Pathol 136:641-655.

17. Scully RE, Young RH, Clement PB: 1998, Tumors of the ovary, maldeveloped gonads, fallopian tube and broad ligament. In: Atlas of tumor pathology, 3rd series, fascicle 23. Armed Forces Institute of Pathology, Washington, DC.

18. Van Niekerk CC, Jap PH, Ramaekers FC, et al.: 1991, Immunohistochemical demonstration of keratin 7 in routinely fixed paraffin-embedded human tissues. J Pathol 165:145-152.

19. Van Niekerk CC, Ramaekers FC, Hanselaar AGJM, et al.: 1993, Changes in expression of differentiation markers between normal ovarian cells and derived tumors. Am J Pathol 142:157-177.

20. Young RH, Scully RE: 1988, Ovarian sex cord-stromal tumors. Problems in differential diagnosis. Pathol Annu 23:237-296. 